\title{
Obesity trends by industry of employment in the United States, 2004 to 2011
}

\author{
Chandra L. Jackson ${ }^{1 *}$, Christina C. Wee ${ }^{2}$, David A. Hurtado ${ }^{3}$ and Ichiro Kawachi ${ }^{4}$
}

\begin{abstract}
Background: Obesity is associated with increased morbidity, occupational injuries, and premature mortality. Obesity also disproportionately affects blacks and socioeconomically disadvantaged workers. However, few studies have evaluated national trends of obesity by employment industry overall and especially by race.

Methods: To investigate national trends of obesity by employment industry overall and by race, we estimated the agestandardized obesity prevalence from 2004 to 2011. We used direct age-standardization with the 2000 US Census population as the standard among 136,923 adults in the US National Health Interview Survey. We also estimated prevalence ratios (PRs) for obesity in black women and men compared to their white counterparts for each employment industry using adjusted Poisson regression models with robust variance.

Results: Obesity prevalence increased for men and women over the study period across all employment industry categories, and the healthcare industry had the highest overall age-standardized prevalence (30\%). Black women had a significantly higher obesity prevalence than white women across all employment industry categories, ranging from 33 \% (95 \% confidence interval (Cl): 1.16,1.52) in Professional/Management to $74 \%$ in Education (95 \% Cl: 1.56,1.93). Obesity prevalence was higher among black than white men for Healthcare $(\mathrm{PR}=1.39[1.15,1.69])$, Education $(\mathrm{PR}=1.39$ $[1.17,1.67])$, Public Administration (PR $=1.34[1.20,1.49])$, and Manufacturing (PR $=1.19[1.11,1.27])$. Differences in obesity prevalence by race were generally widest in professional/management occupations.

Conclusions: Obesity trends varied substantially overall as well as within and between race-gender groups across employment industries. These findings demonstrate the need for further investigation of racial and sociocultural disparities in the work-obesity relationship to employ strategies designed to address these disparities while improving health among all US workers. Further research and interventions among workers in industries with an increasing or high prevalence of obesity should be prioritized.
\end{abstract}

\section{Background}

Obesity, a leading public health problem, is associated with an increased risk of multiple chronic conditions including hypertension, type 2 diabetes, cardiovascular disease, certain cancers (e.g. breast), depression and lower quality of life, disability as well as premature mortality [1-4]. US adults who are full-time employees spend approximately one third of their waking hours at work [5], and there is increasing evidence that adverse working conditions can impact obesity risk $[6,7]$. Studies suggest adults in certain occupations are more likely to be obese, and obesity-in addition to poor health outcomes-is associated with increased occupational

\footnotetext{
* Correspondence: chandra_jackson@hms.harvard.edu

${ }^{1}$ Clinical and Translational Science Center, Harvard Catalyst, Harvard Medical

School, Boston, MA, USA

Full list of author information is available at the end of the article
}

injuries, loss of work-related productivity, and excess healthcare costs [8-10].

Several mechanisms may underlie the occupation-obesity relationship [11, 12]. For instance, obesity may be directly related to occupation through job-related characteristics such as sedentary time (versus physical activity demands), the workplace food environment, work-related stress including job strain, rotating/night shift work, and chemical exposures [13-19]. Individuals working under high-demand, low-control conditions with an effort-reward imbalance are at an increased risk of cardiovascular disease [20], and obesity may be an important contributor. Work demands and pressure likely affect employee eating habits and activity patterns while at work and beyond [3, 21-23]. Additionally, there are indirect effects of occupation on 
obesity because of income disparities that affect the ability to, for example, afford healthy nutrition [24, 25].

Multifactorial interventions to address the obesity epidemic have been implemented across various settings including the workplace, and some populations have begun to experience plateaus in the prevalence of obesity [26]. Worksite wellness programs represent a potentially promising approach to reduce overall obesity as well as racial/ethnic and socioeconomic disparities by focusing on social, cultural and environmental causes of obesity and not just the individual's responsibility [27-36]. Some of these interventions appear effective in terms of achieving clinically meaningful reductions in body weight and improved cardiometabolic risk factor profiles through enhanced nutrition and physical activity [28, 29, 32, 33], although not all studies have yielded positive results [27].

Understanding obesity trends across various industries can provide an important opportunity to identify specific industries that could benefit from worksite interventions and reduce obesity risk. Obese, low socioeconomic status adults are over-represented in certain industries. Moreover, such industries may be disproportionately populated by racial/ ethnic minorities because of the historical connection between race/ethnicity and occupations. Few studies, however, have examined national trends in obesity by industry to identify the industries with the highest rise in obesity. We also sought to address this gap in the literature by examining obesity prevalence trends across gender and race/ethnicity.

\section{Methods}

\section{The National Health Interview Survey}

We analyzed National Health Interview Survey (NHIS) data, which is a series of nationally representative crosssectional surveys. Detailed study procedures have been previously published [37]. In brief, the NHIS uses a stratified cluster probability sampling design to conduct in-person interviews among non-institutionalized US civilians. Trained US Census Bureau interviewers collected data among a probability sample of households throughout the year. Using computer-assisted personal interviewing (CAPI), interviewers obtained information about the health status, healthcare services, health-related behaviors, and sociodemographic characteristics of all members of the sampled household. To provide additional healthrelated information, one adult and one child from each sampled family were randomly selected. The overall response rate for sample adults was $67 \%$ (range: 61-72 \%), each study participant provided NHIS with informed consent, and this study was approved by the Harvard T.H. Chan School of Public Health's institutional review board.

\section{Study participants}

Participants included adults who were $\geq 18$ years old and were self-identified Non-Hispanic white or Non-Hispanic black (hereafter, white and black). We focus on BlackWhite disparities and do not include Hispanics in this particular study because factors (e.g. immigration, culture, acculturation, assimilation) that affect occupational conditions and obesity likely differ by race/ethnicity. Adding an analysis of health disparities along the dimension of ethnicity deserves separate attention. In US data, ethnicity is considered a separate dimension of social stratification as distinct from race (for example, an individual can selfidentify as black Hispanic or white Hispanic). Such inter-sectionality-along with the added complexity of introducing variables associated with immigration and acculturation/assimilation-were considered beyond the scope of this present study. Nevertheless, we acknowledge the importance of future studies investigating potential ethnic differences in obesity trends by employment industry among men and women.

Participants were excluded if they 1) were non-US born; 2) had a body-mass index (BMI) considered extreme $-<15$ or $>70 \mathrm{~kg} / \mathrm{m}^{2} ; 3$ ) were unemployed at the time of the survey; or 4) had missing data (3\%) on BMI, employment industry, or employment status. The final analytic sample included 136,923 employed adults with $30 \%$ considered obese.

\section{Measures \\ Obesity}

We calculated body-mass index (BMI) by dividing selfreported weight in kilograms by self-reported height in meters squared. Obesity was defined as BMI $\geq 30 \mathrm{~kg} / \mathrm{m}^{2}$, overweight as $25.0-29.9 \mathrm{~kg} / \mathrm{m}^{2}$, normal weight as $18.5-$ $24.9 \mathrm{~kg} / \mathrm{m}^{2}$, and underweight as $\mathrm{BMI}<18.5 \mathrm{~kg} / \mathrm{m}^{2}$.

\section{Race/ethnicity}

Participants were asked, 'What race or races do you consider yourself to be?" Participants then chose 1 or more of the following options: white, black/African American, American Indian/Alaskan native, Asian and multiple race. Regarding ethnicity, participants were asked if they were Hispanic or non-Hispanic.

\section{Employment status}

Determined for all adults, employment status during the week prior to the interview was combined as 'working for pay at a job/business', 'working (but not for pay) at a family owned job/business,' 'with a job/business but not at work', 'unemployed and looking for work', and 'not working at a job or business and not looking for work.' Unemployed participants were not included in this study.

\section{Industry of employment}

For stable estimates to investigate potential disparities, we categorized the North American Industrial Classification System (NAICS) codes into eight meaningful categories, including: 1) 'Agriculture, Fishing, Forestry, and Hunting 
Industries'; 'Mining Industries'; 'Utilities Industries'; 'Construction Industries'; 'Manufacturing Industries'; and 'Wholesale Trade Industries'; and 'Transportation and Warehousing Industries', 2) 'Retail Trade Industries', 3) 'Information Industries'; 'Finance and Insurance Industries'; and 'Real Estate and Rental and Leasing Industries', 4) 'Professional, Scientific, and Technical Services Industries'; 'Management of Companies and Enterprises Industries'; and 'Administrative and Support and Waste Management and Remediation', 5) 'Education Services Industries', 6) 'Health Care and Social Assistance Industries', 7) 'Accommodation and Food Services Industries' as well as 8) 'Other Services (except Public Administration) Industries'; 'Public Administration Industries;' and 'Arts, Entertainment, and Recreation Industries.'

\section{Occupation}

Adults who ever worked, were working (paid or non-paid) during the week prior to the survey, or who were not at work the week before the survey (although they had a job or business) were asked about their occupation, which was categorized based on the Standard Occupational Classification System codes. We combined occupation categories into 'Professional/management', 'Support Services' and 'Laborers' based on type of work. Based on current, longest held, or most recently held job or work situation, class of work/occupation was categorized as either 1) an employee for wages, salary, or commission at a private company, business, or for an individual; 2) an employee for a federal, state, or local government; 3) self-employed (business, professional practice or farm); or 4) working without pay in a family-owned business or farm.

\section{Other socioeconomic factors}

Educational attainment was classified as either less than high school (no high school diploma), high school (high school or general equivalency diploma), some college, and a college education or greater. Household annual income was stratified at above and below $\$ 35,000$. Poverty status was determined as being below the poverty line after considering total income from all sources before taxes among all members of the family.

\section{Health behaviors}

Lifetime alcohol consumption and smoking status were both categorized as 'never,' 'current,' or 'former.' Physical activity during leisure time was classified as 'none', 'low', or 'high'; participants engaging in some level of physical activity and providing a particular number of activity bouts were stratified at the midpoint and categorized as 'low' or 'high.' Participants reporting 'never' or 'unable to do this type activity' were categorized as 'none.' Sample adults reported how many hours of sleep they, on average, get in a 24-h period, which was categorized as $<7 \mathrm{~h}, 7$ to $9 \mathrm{~h}$, and $>9 \mathrm{~h}$.

\section{Covariates}

Age was categorized as $18-49$ years, $50-64$ years, as well as $\geq 65$ years. Marital status was classified as never married, married/living with partner, or divorced/separated/ widowed. General health status (based on self report) was characterized as excellent/very good, good, or fair/ poor. US geographic regions were considered as the South, Midwest, Northeast, and West.

\section{Statistical analysis}

We pooled eight survey years (2004-2011) of NHIS data using the Integrated Health Interview Series [38]. Sampling weights were used for all analyses to account for the unequal probabilities of selection to participate in the study, nonresponse bias, and oversampling of specific subgroups (e.g. racial/ethnic minorities; elderly individuals $65+$ years of age). Standard errors were calculated using Taylor series linearization [39]. STATA statistical software version 12 (STATA Corporation, College Station, Texas, USA, 2007) was used for these analyses [40].

Continuous variables were presented as means \pm standard errors (SE), and categorical variables were illustrated as absolute values with percentages. To take survey weights into account, Rao-Scott second-order corrected Pearson statistics were employed to test for differences in pre-specified sociodemographic, clinical, and behavioral characteristics overall and between blacks and whites as well as obesity status [41].

To estimate prevalence ratios for obesity overall and among black men and women separately compared to obesity in their white counterparts by employment industry category and occupation with corresponding $95 \%$ confidence intervals, we used 4 different Poisson regression models with robust variance estimation [42]. Pre-specified demographic, health behavior, and occupational characteristics were introduced into the model as a group in a sequential manner. Whites were the reference category for all Black-White comparisons because whites were the largest racial group in this sample, thereby providing greater statistical stability. For models stratified by race and a separate model including an interaction term for race and obesity, we adjusted for age in 3 categories: $18-49,50-64,65+$ years in the first model, then for sociodemographic factors (e.g. gender, marital status, educational attainment, household income) in the second model. We then adjusted for class of occupation and occupation. We subsequently adjusted for health behaviors, including alcohol consumption, smoking status, leisure-time physical activity and sleep duration to explore the extent to which obesity prevalence may be explained by these lifestyle factors. We also adjusted for prevalent medical conditions (i.e. hypertension, diabetes, cancer, heart disease).

Testing for temporal trends in BMI over time by race and employment industry category, we repeated our analyses stratified by industry and then separately by blacks 
and whites. Direct standardization for age using the 2000 US Census as the standard population was employed to obtain age-adjusted obesity prevalence estimates. We included interaction terms for race and survey year with 2 years combined in separate linear regression models to investigate possible Black-White differences in BMI prevalence over the study period. In subsequent analyses, we also investigated temporal trends in employment by race-gender groups.

\section{Results}

\section{Study population characteristics}

Among the 136,923 participants, mean age was 47 years, $50 \%$ were women, $13 \%$ were black, $28 \%$ (30 for whites; 17 for blacks) had at least a college education, and $30 \%$ were obese. Table 1 presents weighted estimates of agestandardized obesity prevalence by study population characteristics (i.e. sociodemographic, health behavior, occupational, clinical) among black and white participants. Black women (46 vs. $27 \%$ ) and black men (35 vs. $29 \%$ ) were more likely to be obese than their white counterparts.

\section{Obesity prevalence and trends by industry of employment} Participants employed in the healthcare industry had the highest overall age-standardized prevalence of obesity (32\%), while those in the education industry had the lowest (26\%). Figure 1 illustrates temporal trends from 2004 to 2011 for age-standardized prevalence of obesity by industry of employment overall and among black and white men and women. The prevalence of obesity appeared to increase for men and women over the study period across all employment industry categories. Women had a particularly high prevalence for health care and food/accommodation services, while men in the education sector experienced the greatest increase in obesity prevalence over time.

Black-white differences in obesity by industry of employment Table 2 presents age- and fully-adjusted prevalence ratios of obesity for blacks compared to whites by gender and industry of employment category. Compared to white women, black women had a significantly higher prevalence of obesity across all industries of employment (74\% excess prevalence in Education [95\% confidence interval (CI): 1.56, 1.93], 61 \% [95 \% CI: 1.46, 1.78] in Public Administration, 53 \% [95 \% CI: 1.33-1.77] in Food/Accommodation Services, $52 \%$ [95 \% CI: 1.39-1.67] in Manufacturing/Construction/Agriculture, $40 \%$ [95 \% CI: 1.24-1.57] in Retail, 37 \% [95 \% CI: 1.21-1.56] in Finance/ Information, $44 \%$ [95 \% CI: 1.34-1.54] in Healthcare, and 33 \% [95 \% CI: 1.16, 1.52] in Professional/Management).

Compared to white men, multivariable-adjusted obesity was more prevalent in black men employed in the following industries: Healthcare ( $\mathrm{PR}=1.39$ [95 \% CI: 1.15, 1.69]), Education $(\mathrm{PR}=1.39$ [95 \% CI: 1.17, 1.67]), Public
Administration ( $\mathrm{PR}=1.34$ [95 \% CI: 1.20, 1.49]), and Manufacturing/Construction/Agriculture $(\mathrm{PR}=1.19$ [95 \% CI: $1.11,1.27])$. Obesity prevalence, however, was not different between black and white men in Retail, Finance/Information services, Professional/Management, and Food/Accommodation services industries. Demographics, occupational characteristics, and health behaviors did not substantially attenuate the obesity prevalence estimates for men and women. The supplemental table displays age-standardized prevalence of obesity by industry of employment among black and white men and women by each industry of employment without combining industries.

\section{Race-specific obesity prevalence trends by employment industry}

Obesity prevalence significantly increased over the study period among black women in Finance/Information [35 \% $(28.2,41.7)$ vs. $48 \%(42.0,55.0)]$ and Food/Accommodation services [37 \% $(29.4,44.6)$ vs. $51 \%(44.7$, 57.2)] industries, while obesity prevalence significantly increased in Finance/Information [22 \% (19.4, 23.7) vs. $27 \%$ (24.1, 29.6)], Healthcare [27 \% (25.7, 29.0) vs. $31 \%$ $(29.2,33.5)]$, and Food/Accommodation services [25 \% $(21.9,28.5)$ vs. $32 \%(28.7,35.9)]$ industries among white women (see Figure 1). Obesity prevalence was consistently higher among black women compared to white women over the study period in all industries.

Obesity prevalence significantly increased from 2004 to 2011 among black men in Manufacturing/Construction [34 \% (30.3, 36.8) vs. $41 \%(37.4,44.5)]$, Professional/Management $[22 \%(15.1,27.0)$ vs. $41 \%(33.6,48.1)]$, and Public Administration $[34 \%(28.4,39.3)$ vs. $45 \%(40.3,51.5)]$ industries. Among white men, obesity prevalence significantly increased only in Manufacturing/Construction [28 \% $(27.3,29.7)$ vs. $32 \%(30.3,33.1)]$. The disparity in obesity appeared to decrease over time in Education while it appeared to increase over time in Professional management and Public Administration industries.

\section{Black-white differences in obesity by occupation within industry of employment}

Table 3 shows the age-standardized prevalence of obesity by occupation within industry of employment overall and by race and gender. Obesity prevalence was higher among black men and women compared to their white counterparts in all occupations (except for men in support services occupations in Professional/Management services [26 vs. $27 \%$ ]). Obesity prevalence among black men and women widened with higher proportions of professionals within occupations for the Food/Accommodation services industry category. Furthermore, differences in obesity prevalence between blacks and whites for both women and men generally narrowed among laborers but increased among those in professional/ management occupations. 
Table 1 Age-standardized prevalence of obesity by demographic, occupational, health behavior and clinical characteristics among 136,923 US black and white men and women, National Health Interview Survey, 2004-2011

\begin{tabular}{|c|c|c|c|c|c|}
\hline & Overall & Black women & White women & Black men & White men \\
\hline & $\%(95 \% \mathrm{Cl})$ & $\%(95 \% \mathrm{Cl})$ & $\%(95 \%$ Cl) & $\%(95 \% \mathrm{Cl})$ & $\%(95 \% \mathrm{Cl})$ \\
\hline Overall sample size & 136,923 & 15,277 & 58,784 & 10,023 & 52,839 \\
\hline Obese & $30(29.3-30.1)$ & $46(45.3-47.6)$ & $27(26.3-27.4)$ & $35(34.0-36.5)$ & $29(28.7-29.7)$ \\
\hline \multicolumn{6}{|l|}{ Age group } \\
\hline $18-49$ & $29(28.8-29.8)$ & $45(43.7-46.5)$ & $25(24.6-26.0)$ & $39(37.5-40.9)$ & $29(28.1-29.6)$ \\
\hline $50-64$ & $33(32.3-33.6)$ & $51(48.9-53.2)$ & $30(29.3-31.2)$ & $35(32.4-37.0)$ & $33(32.0-33.9)$ \\
\hline$\geq 65$ & $25(24.4-25.6)$ & $41(39.0-43.7)$ & $24(23.0-24.8)$ & $29(26.9-31.8)$ & $24(22.8-24.7)$ \\
\hline \multicolumn{6}{|l|}{ Educational attainment } \\
\hline$<$ High school & $33(32.5-33.8)$ & $47(45.7-49.2)$ & $31(30.2-32.1)$ & $35(32.7-37.3)$ & $33(31.6-33.4)$ \\
\hline High school graduate & $37(35.3-37.8)$ & $53(50.6-55.8)$ & $35(32.8-37.0)$ & $37(34.0-40.1)$ & $34(31.9-35.3)$ \\
\hline Some college & $32(31.1-32.4)$ & $46(44.1-48.0)$ & $29(28.2-30.0)$ & $36(33.9-38.4)$ & $32(30.5-32.5)$ \\
\hline$\geq$ College & $22(21.9-23.0)$ & $40(37.3-42.4)$ & $19(18.4-20.0)$ & $34(30.4-37.5)$ & $23(22.5-24.1)$ \\
\hline \multicolumn{6}{|l|}{ Marital status } \\
\hline Married & $29(28.7-29.6)$ & $46(44.2-47.9)$ & $26(24.8-26.2)$ & $38(36.2-40.1)$ & $31(30.0-31.2)$ \\
\hline Divorced/separated/widowed & $31(30.3-31.6)$ & $47(45.4-49.0)$ & $29(28.3-30.1)$ & $34(32.1-36.4)$ & $28(26.7-28.8)$ \\
\hline Never married & $31(29.8-31.8)$ & $46(43.7-48.5)$ & $33(31.0-34.4)$ & $33(29.5-36.0)$ & $25(23.3-26.2)$ \\
\hline Living in poverty & $38(36.4-38.6)$ & $51(48.7-53.1)$ & $38(35.9-39.4)$ & $34(31.2-37.0)$ & $31(28.7-32.9)$ \\
\hline Household income $<\$ 35,000$ & $35(34.0-35.3)$ & $50(48.2-51.0)$ & $35(33.6-35.5)$ & $34(32.2-35.4)$ & $30(28.7-30.8)$ \\
\hline \multicolumn{6}{|l|}{ Class of worker } \\
\hline Private wage & $30(29.6-30.5)$ & $46(45.1-47.8)$ & $28(27.0-28.3)$ & $34(32.9-35.8)$ & $29(28.8-30.1)$ \\
\hline Government & $30(29.8-31.1)$ & $47(45.0-49.2)$ & $26(25.0-26.9)$ & $39(36.1-41.2)$ & $31(29.5-32.0)$ \\
\hline Self employed & $26(24.7-26.6)$ & $41(35.5-46.0)$ & $22(20.7-23.5)$ & $34(29.0-39.2)$ & $27(25.2-27.8)$ \\
\hline \multicolumn{6}{|l|}{ Occupation } \\
\hline Professional/management & $26(25.5-26.9)$ & $42(38.8-45.3)$ & $24(22.5-24.5)$ & $35(31.8-38.6)$ & $27(25.6-27.5)$ \\
\hline Support services & $28(27.9-28.9)$ & $46(44.9-47.7)$ & $26(25.5-26.8)$ & $34(31.5-36.8)$ & $27(26.1-28.2)$ \\
\hline Laborers & $34(33.2-34.3)$ & $49(46.6-50.7)$ & $33(31.6-33.9)$ & $36(34.4-37.2)$ & $32(31.4-32.8)$ \\
\hline \multicolumn{6}{|l|}{ Industry } \\
\hline Manufacturing/construction & $31(30.5-31.6)$ & $47(44.0-49.6)$ & $28(26.6-28.9)$ & $35(33.4-36.9)$ & $31(30.1-31.6)$ \\
\hline Retail & $30(28.6-30.6)$ & $44(39.7-47.5)$ & $28(26.4-29.3)$ & $33(27.8-38.2)$ & $29(27.7-31.0)$ \\
\hline Finances/information & $27(26.0-28.1)$ & $42(38.0-46.1)$ & $26(24.9-28.1)$ & $32(26.7-37.7)$ & $25(23.6-26.7)$ \\
\hline Profess/admin/man & $27(26.0-28.1)$ & $43(39.4-47.0)$ & $25(23.4-26.3)$ & $32(27.4-36.2)$ & $27(24.9-28.1)$ \\
\hline Education & $26(25.0-26.8)$ & $46(42.8-49.0)$ & $22(20.9-23.3)$ & $38(33.4-42.8)$ & $28(25.6-29.5)$ \\
\hline Health care & $32(31.3-33.1)$ & $51(48.5-52.9)$ & $30(28.7-30.9)$ & $37(31.8-41.7)$ & $25(22.4-26.7)$ \\
\hline Accommodation and food & $31(29.4-32.8)$ & $48(43.2-51.9)$ & $29(27.1-31.5)$ & $33(27.6-39.2)$ & $28(24.5-30.9)$ \\
\hline Public administration, arts & $31(29.8-31.5)$ & $44(41.8-46.8)$ & $27(25.3-27.8)$ & $39(35.9-42.2)$ & $30(29.0-32.0)$ \\
\hline \multicolumn{6}{|l|}{ Health behaviors } \\
\hline \multicolumn{6}{|l|}{ Sleep duration } \\
\hline$<7 \mathrm{~h}$ & $34(33.6-34.9)$ & $49(47.2-50.7)$ & $32(31.0-33.0)$ & $38(35.6-39.9)$ & $33(31.8-33.8)$ \\
\hline 7 to $9 \mathrm{~h}$ & $27(26.9-27.7)$ & $45(43.2-46.0)$ & $24(23.7-24.9)$ & $34(32.5-35.7)$ & $27(26.8-28.0)$ \\
\hline$>9 \mathrm{~h}$ & $37(35.1-38.9)$ & $51(46.4-55.7)$ & $36(32.8-38.5)$ & $34(28.3-39.0)$ & $35(32.0-38.4)$ \\
\hline \multicolumn{6}{|l|}{ Smoking status } \\
\hline Never & $30(29.4-30.5)$ & $47(45.7-48.5)$ & $26(25.8-27.2)$ & $38(36.1-40.2)$ & $30(28.2-29.8)$ \\
\hline Current & $32(31.5-32.9)$ & $53(50.6-56.2)$ & $29(27.9-29.9)$ & $39(36.6-41.5)$ & $33(31.9-33.7)$ \\
\hline
\end{tabular}


Table 1 Age-standardized prevalence of obesity by demographic, occupational, health behavior and clinical characteristics among 136,923 US black and white men and women, National Health Interview Survey, 2004-2011 (Continued)

\begin{tabular}{|c|c|c|c|c|c|}
\hline Former & $25(24.5-25.8)$ & $39(36.2-41.2)$ & $24(23.3-25.3)$ & $26(23.9-27.9)$ & $24(22.9-25.0)$ \\
\hline \multicolumn{6}{|l|}{ Alcohol consumption } \\
\hline Never & $34(32.6-34.4)$ & $47(45.2-49.2)$ & $31(29.8-32.3)$ & $35(31.5-37.9)$ & $30(28.7-32.0)$ \\
\hline Current & $27(26.6-27.5)$ & $43(41.2-45.0)$ & $24(23.0-24.3)$ & 35 (32.8-36.6) & $28(27.2-28.5)$ \\
\hline Former & $36(34.9-36.6)$ & $50(46.6-52.6)$ & $35(34.1-36.7)$ & $36(33.7-39.2)$ & $34(32.2-35.1)$ \\
\hline \multicolumn{6}{|c|}{ Leisure-time physical activity } \\
\hline Never/unable & $36(34.9-36.1)$ & $48(46.8-50.0)$ & $34(33.4-35.4)$ & $36(32.7-34.5)$ & $34(32.7-34.5)$ \\
\hline Low & $30(29.2-30.5)$ & $46(43.8-47.6)$ & $26(25.6-27.2)$ & $38(35.6-40.4)$ & $30(29.3-31.2)$ \\
\hline High & $23(22.7-23.9)$ & $43(40.6-45.1)$ & $20(19.2-20.8)$ & $32(29.3-34.2)$ & $24(23.0-24.7)$ \\
\hline \multicolumn{6}{|l|}{ Clinical characteristics } \\
\hline Hypertension (yes) & $45(44.5-45.8)$ & $58(56.2-59.4)$ & $43(42.2-44.5)$ & $47(45.2-49.2)$ & $44(42.6-44.6)$ \\
\hline Diabetes (yes) & $58(56.8-59.4)$ & $69(67.0-72.0$ & $58(55.7-60.0)$ & $56(52.4-58.7)$ & $56(53.4-57.9)$ \\
\hline Heart disease (yes) & $36(34.7-36.9)$ & $55(51.3-57.7)$ & $33(31.7-34.9)$ & $43(38.2-47.3)$ & $35(33.4-36.8)$ \\
\hline Cancer (yes) & $29(28.1-30.5)$ & $49(44.2-52.8)$ & $29(27.0-30.2)$ & $44(36.2-52.3)$ & $28(25.5-29.8)$ \\
\hline \multicolumn{6}{|l|}{ Health status } \\
\hline Excellent/very good & $22(22.0-22.9)$ & $36(34.3-37.4)$ & 19 (18.7-19.9) & $30(27.9-31.4)$ & $23(22.7-23.9)$ \\
\hline Good & $38(37.7-39.0)$ & $50(48.2-51.9)$ & 37 (36.0-38.0) & $38(36.0-40.6)$ & $37(36.4-38.3)$ \\
\hline Fair/poor & $46(44.6-46.5)$ & $60(57.6-61.8)$ & $45(43.4-46.5)$ & $43(40.2-45.5)$ & $43(41.1-44.2)$ \\
\hline \multicolumn{6}{|l|}{ Region of country } \\
\hline Northeast & $28(27.2-29.0)$ & $44(40.3-46.9)$ & $25(23.7-26.4)$ & $34(31.2-37.1)$ & $29(27.7-30.3)$ \\
\hline Midwest & 31 (30.4-31.9) & $45(43.0-47.0)$ & $29(28.3-30.5)$ & 37 (33.7-40.1) & $31(30.1-31.8)$ \\
\hline South & 31 (30.6-31.8) & $48(46.5-49.4)$ & $27(26.1-27.9)$ & $35(33.5-36.5)$ & $30(29.0-31.0)$ \\
\hline West & $26(24.8-26.3)$ & $43(39.0-47.0)$ & $24(23.2-25.4)$ & $34(29.4-37.8)$ & $25(24.1-26.4)$ \\
\hline
\end{tabular}

In subsequent analyses, we found that employment status (employed vs. unemployed) in each industry remained similar for each racial group throughout the study period, and blacks were consistently more likely to be obese in each industry (see Additional file 1).

\section{Discussion}

We found that the prevalence of obesity and obesity trends varied substantially by industries of employment and occupation overall as well as within and between race-gender groups. Participants employed in the healthcare industry had the highest overall age-standardized prevalence $(30 \%)$ while those in the education industry had the lowest (26\%). The prevalence of obesity appeared to increase for men and women over the study period across employment industry, and women had a particularly high prevalence for health care and food/accommodation services. Men in the education industry experienced the greatest increase in obesity prevalence over time.

Ironically, participants employed in the healthcare industry (32\%) had the highest overall age-standardized prevalence of obesity followed by food/accommodation services (31\%) and public administration (31\%). It is surprising that health care workers have the highest obesity rates because those in the healthcare industry are charged with advising the rest of the nation about healthy body weight recommendations. Of note, Bandura's social learning theory suggests that patients are more likely to listen to health professionals if they serve as role models for the behaviors they tout or recommend. Our findings, along with those from $\mathrm{Gu}$ et. al., suggest the need to further study and intervene among workers in the healthcare industry given the overall high prevalence of obesity in this particular industry [43]. Furthermore, it should be noted that food industry workers often have to get up in the middle of the night to prepare food. These workers also work in, for instance, fast food chains that are open 24/7. Job conditions in both of these sectors may result in behaviors like extra snacking. The irregular sleep hours may also contribute to sleep deprivation, which has been shown to be associated with increased appetite and caloric intake.

As suggested by our study, along with previous investigations of overall obesity by employment industry category, complex aspects of the work environment that include 


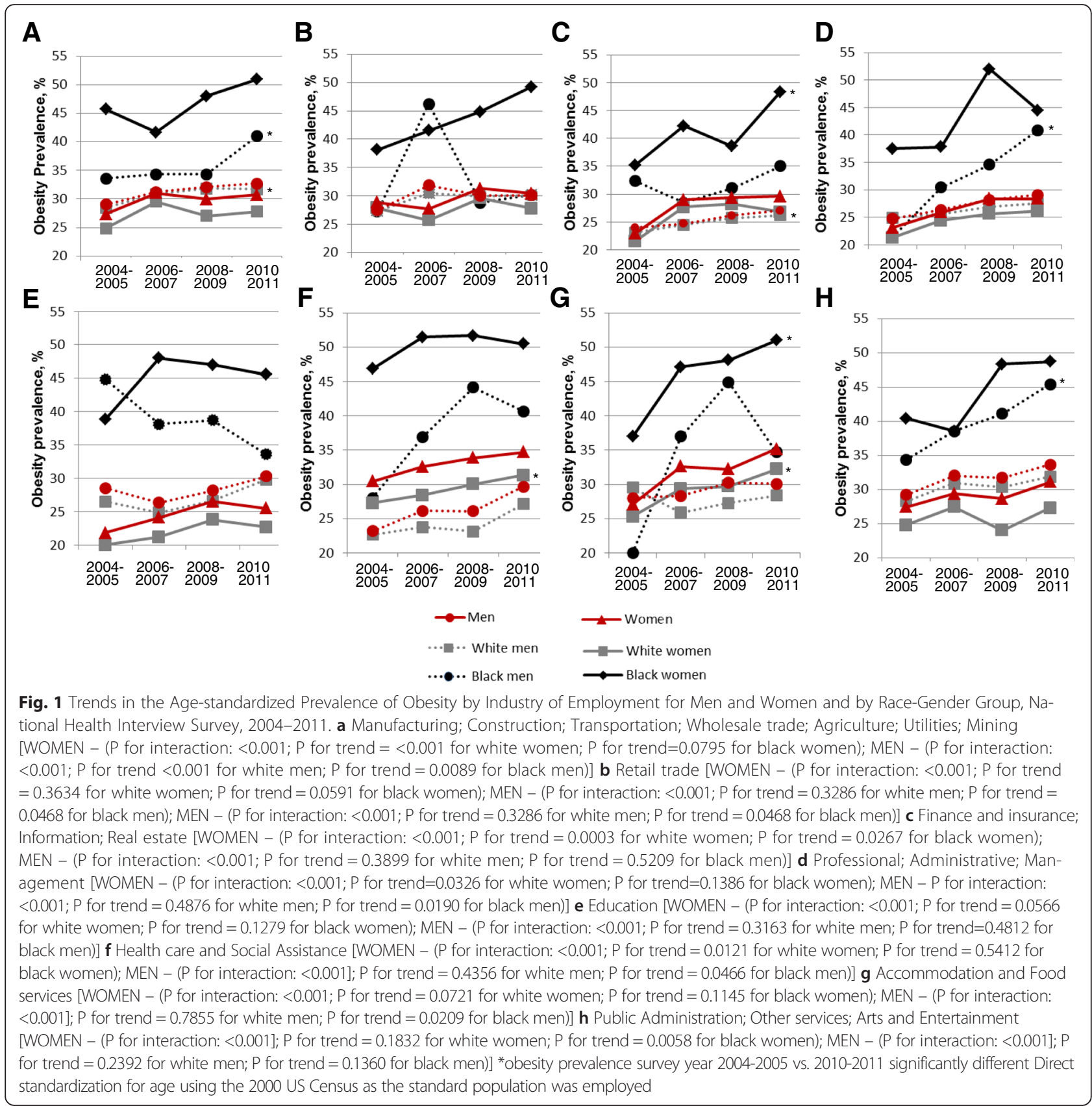

inequitably distributed features likely influence population patterns of obesity [44-46]. For instance, both health care and food/accommodation services are known for requiring long and irregular working hours with inadequate rest/ breaks and shift work; these factors are directly and indirectly associated with an excess of calories and metabolic/circadian deregulations.

Some hypothesized mechanisms by which the work environment could facilitate a differential prevalence of obesity include: 1) food environments in or around the workplace could enhance consumption of foods that increase obesity risk and vice versa; 2) physical environments or job requirements could increase the likelihood of sedentary activities during work hours; 3 ) job stress could affect lifestyle behaviors (e.g. alcohol drinking patterns, smoking, sedentary tendencies, sleep hygiene) related to obesity or weight gain; 4) coworker behaviors (e.g. eating habits; activity patterns) may negatively or positively influence the behaviors of other workers; 5) psychological job strain could modify endocrine factors associated with obesity; and 6) long work hours, shift work, and working overtime could lead to fatigue and promote behaviors (e.g. short sleep duration) that increase obesity risk while inhibiting behaviors associated with the prevention of weight gain and 
Table 2 Adjusted prevalence ratios of obesity for black compared to white women and men by industry of employment, National Health Interview Survey, 2004-2011 ( $n=136,923)$

\begin{tabular}{|c|c|c|c|c|c|c|c|c|}
\hline & \multicolumn{2}{|c|}{ Model 1 $1^{\text {a. }}$ Age } & \multicolumn{2}{|c|}{ Model $2^{\text {b}}$ : Demographics } & \multicolumn{2}{|c|}{ Model 3`: Occupational characteristics } & \multicolumn{2}{|c|}{ Model 4d: Health Behaviors } \\
\hline & $P R$ & $95 \% \mathrm{Cl}$ & PR & $95 \% \mathrm{Cl}$ & PR & $95 \% \mathrm{Cl}$ & PR & $95 \% \mathrm{Cl}$ \\
\hline & \multicolumn{8}{|c|}{ WOMEN } \\
\hline Manufacturing/construction & 1.72 & $(1.60-1.84)$ & 1.66 & $(1.54-1.80)$ & 1.61 & $(1.49-1.75)$ & 1.52 & $(1.39-1.67)$ \\
\hline Retail & 1.55 & $(1.41-1.70)$ & 1.49 & $(1.34-1.65)$ & 1.48 & $(1.34-1.65)$ & 1.40 & $(1.24-1.57)$ \\
\hline Finances/information & 1.60 & $(1.45-1.77)$ & 1.55 & $(1.38-1.73)$ & 1.53 & $(1.37-1.72)$ & 1.37 & $(1.21-1.56)$ \\
\hline Profess/admin/man & 1.74 & $(1.57-1.93)$ & 1.45 & $(1.28-1.64)$ & 1.40 & $(1.23-1.59)$ & 1.33 & $(1.16-1.52)$ \\
\hline Education & 2.05 & $(1.88-2.23)$ & 1.87 & $(1.70-2.06)$ & 1.85 & $(1.68-2.04)$ & 1.74 & $(1.56-1.93)$ \\
\hline Health care and social services & 1.70 & $(1.62-1.80)$ & 1.53 & $(1.44-1.63)$ & 1.53 & $(1.43-1.62)$ & 1.44 & $(1.34-1.54)$ \\
\hline Accommodation and food & 1.67 & $(1.50-1.87)$ & 1.62 & $(1.44-1.84)$ & 1.60 & $(1.42-1.82)$ & 1.53 & $(1.33-1.77)$ \\
\hline \multirow[t]{3}{*}{ Public administration, arts } & 1.76 & $(1.63-1.90)$ & 1.73 & $(1.59-1.89)$ & 1.74 & $(1.59-1.89)$ & 1.61 & $(1.46-1.78)$ \\
\hline & PR & $95 \% \mathrm{Cl}$ & PR & $95 \% \mathrm{Cl}$ & PR & $95 \% \mathrm{Cl}$ & PR & $95 \% \mathrm{Cl}$ \\
\hline & \multicolumn{8}{|c|}{ MEN } \\
\hline Manufacturing/construction & 1.18 & $(1.11-1.25)$ & 1.23 & $(1.16-1.31)$ & 1.22 & $(1.15-1.30)$ & 1.19 & $(1.11-1.27)$ \\
\hline Retail & 1.14 & $(0.99-1.32)$ & 1.16 & $(1.00-1.36)$ & 1.16 & $(1.00-1.35)$ & 1.09 & $(0.92-1.29)$ \\
\hline Finances/information & 1.27 & $(1.09-1.48)$ & 1.22 & $(1.04-1.44)$ & 1.21 & $(1.03-1.43)$ & 1.18 & $(0.99-1.41)$ \\
\hline Profess/admin/man & 1.30 & $(1.14-1.47)$ & 1.24 & $(1.08-1.42)$ & 1.23 & $(1.07-1.41)$ & 1.16 & $(0.99-1.35)$ \\
\hline Education & 1.39 & $(1.20-1.62)$ & 1.42 & $(1.20-1.67)$ & 1.40 & $(1.19-1.65)$ & 1.39 & $(1.17-1.67)$ \\
\hline Health care and social services & 1.51 & $(1.30-1.77)$ & 1.48 & $(1.24-1.76)$ & 1.49 & $(1.25-1.77)$ & 1.39 & $(1.15-1.69)$ \\
\hline Accommodation and food & 1.30 & $(1.08-1.56)$ & 1.32 & $(1.08-1.62)$ & 1.33 & $(1.09-1.63)$ & 1.25 & $(0.99-1.58)$ \\
\hline Public administration, arts & 1.35 & $(1.23-1.48)$ & 1.45 & $(1.32-1.60)$ & 1.43 & $(1.30-1.58)$ & 1.34 & $(1.20-1.49)$ \\
\hline
\end{tabular}

PR Prevalence Ratio, CI Confidence Interval

${ }^{a}$ Model 1 - adjusted for age categories

${ }^{\mathrm{b}}$ Model 2 - adjusted Model 1 + gender, marital status, educational attainment, household income, living in poverty

cModel 3 - adjusted Model 2 + class of occupation, occupation

${ }^{\mathrm{d}}$ Model 4 - adjusted Model 3 + smoking status, alcohol consumption, physical activity, sleep duration

abdominal fat accumulation [21]. Short sleep, as a predictor of obesity, likely contributed, in part, to the racial/ethnic disparities in obesity trends we observed by industry of employment. In a previous study, we found that blacks were more likely to be short sleepers ( $<7 \mathrm{~h}$ within a 24 -h period) than whites ( 37 vs. $28 \%$ ), that the black-white disparity was widest among professional occupations across industries of employment, and short sleep duration increased with increasing professional roles among blacks and decreased in whites [47-49]. Our cross-sectional approach to a mediation analysis of health behaviors, however, did not support the claim that health behaviors including sleep made a substantial contribution towards explaining overall racial differences in obesity by employment industry. Further research, perhaps by socioeconomic status within racial groups, is needed as black professionals, for instance, could experience unique factors (e.g. John Henryism or healthdamaging work ethic to overcome adversity and succeed with limited resources; financial strain due to limited wealth; greater home stress) that contribute to obesity. Such findings could be masked when racial groups are analyzed as a monolith.

Black women had a significantly higher prevalence of obesity than white women across all industries of employment. Obesity prevalence was higher among black than white men in the Healthcare, Education, Public Administration, and Manufacturing sectors while nonsignificantly higher in most other industries. Men in the education industry experienced the greatest increase in obesity prevalence over time. These patterns in obesity among black men and women workers are consistent with other studies showing that blacks are also more likely than their white counterparts to report job stress and discrimination. Moreover, blacks tend to work more than one low-wage job and have positions with limited control over job demands in addition to being more likely to live in poverty despite employment [50-55].

Racial/ethnic disparities in obesity may be propagated through differential exposure to structural and informal workplace social hazards, which may create or exacerbate 
Table 3 Age-standardized prevalence of obesity by occupation within industries overall and among 136,923 black and white men and women, National Health Interview Survey, 2004 to 2011

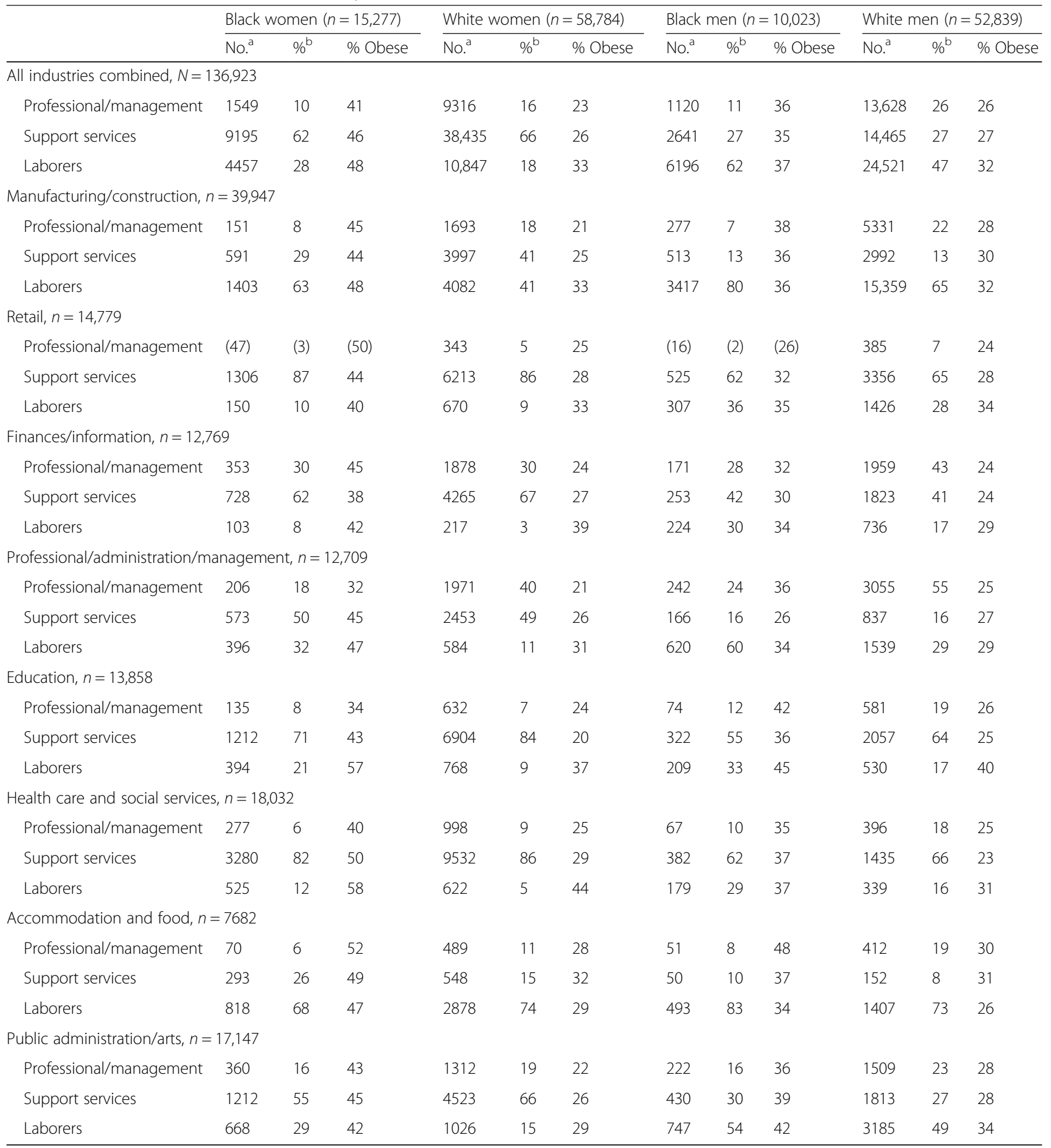

Percentages are weighted estimates; the sample sizes are unweighted

a = Sample size for the entire race-gender subgroup; \%

$\mathrm{b}=$ Percentage for the entire race-gender subgroup; ()$=$ estimates based on small sample size, which means less than 50 participants

stressors that increase the likelihood of obesity. For instance, exposure to historical (e.g. overt racism) and contemporary forms (e.g. microaggressions, subtle indignities) of workplace discrimination and in broader society may contribute to psychosocial stress (e.g. depression, stereotype threat) as well as job strain or effort-reward imbalance [56-58]. Furthermore, shift work is more common in racial/ethnic minorities $[59,60]$, which may, at 
least partially, explain the racial differences in obesity by industry and occupation. Flatter inverse gradients between some socioeconomic status (SES) measures like occupation and common health-related outcomes among blacks compared to whites may also partially be explained by the higher obesity prevalence and subsequent disease risk among even blacks of higher SES [61]. It has been shown that blacks have more risk factors for comorbid conditions (e.g. obesity, hypertension, type 2 diabetes, sleep apnea) that may influence ones working conditions $[62,63]$. Future research is needed in these areas.

Although future research is necessary, it is also possible that some industries could have become more or less biased towards hiring overweight individuals of any race over time. Even within the same industry, black workers and especially women, were more likely to be obese than their white counterparts, which generally remained consistent across the study period. Revealing a complex relationship between obesity and wages by race-gender group, Cawley et. al. found that overweight appears to lower the wages of white women while heavier black women as well as Hispanic women and men have lower wages that results from unobserved heterogeneity [64]. One potential explanation for the observation among white women was related to heavier white women being more likely to have a lower self-esteem than, for instance, black women. It is also possible that overweight white women face more discrimination in the workplace (e.g. getting hired, getting promoted) than other groups. Moreover, heavier black men had higher wages, which was apparently driven by underweight black men earning less compared to black men with healthy body weights rather than heavier black men earning more. Regarding the potential influence of occupations on the obesity epidemic and disparities, Lakdawalla and Philipson have hypothesized that technological changes have contributed to increased body weights by making lifestyles more sedentary. The authors also noted that technological influence varies by occupational class or socioeconomic status as well as race [65]. Furthermore, individuals with chronic health conditions (e.g. diabetes, cancer, heart disease) can influence occupational opportunities. For example, someone employed as a laborer might have a myocardial infarction and become a supermarket bagger since that job requires less strenuous physical activity. The health condition might, therefore, be a common prior cause of the cross-sectional occupation as well as change in BMI.

This study has limitations. First, we could not prospectively investigate employment industry and obesity risk among the employed due to the cross-sectional study design. We also relied on self-reported data. According to most studies, blacks and whites do not self-report their height and weight differently [66-71]; fewer studies have reported small differences [72-74]. Also, there was no access to data on diet/nutrition and medication use, which could influence obesity risk and differ by race. Furthermore, employment status was based on participants being employed during the week prior to the interview, and the impact of job security can be more variable for lower-SES and minority groups [75]. Studies investigating the influence of job security on obesity disparities would be useful. Furthermore, categories of occupation are broad and may include considerable heterogeneity. For instance, our categories likely correlate with wealth and some may include a disproportionate number of shift workers that we were unable to account for although shift work has been shown to differ by race and negatively impact obesity risk [45]. Lastly, we do not have residential data to account for the impact of racial residential segregation, which has been shown to influence health [76]. Importantly, Bleich et al. found no racial disparities in obesity among poor black and white women with a similar environmental context and income [77].

Despite the limitations, our study has important strengths and contributes to the public health literature. For instance, we had access to data on a large sample size overall and among black participants for which data is often scarce. The large sample size allowed for robust interaction testing along with racial, industry, and occupational stratification. Furthermore, we had eight consecutive years of industry data, which enhanced our power to investigate trends. Our data are also nationally representative and were recently collected. For easier interpretation of the data, we directly estimated prevalence ratios instead of odds ratios.

\section{Conclusions}

Black-White differences in obesity varied by industry of employment and occupation, and have not appeared to change substantially over time. These findings demonstrate the need for further investigation of racial and sociocultural disparities in the work-obesity relationship to employ strategies designed to address disparities while improving health among all US workers. Interventions that prioritize workers who are employed in industries with high or increasing obesity are needed.

\section{Additional file}

Additional file 1: Table S1. Age-Standardized Prevalence of Obesity by Industry of Employment among 136,923 US Black and White Men and Women, National Health Interview Survey, 2004-2011. (DOCX 14 kb)

Competing interests

The authors do not have competing interests to declare. 


\section{Authors' contributions}

Study concept and design: Jackson. Acquisition of data: Jackson. Statistical analysis: Jackson. Interpretation of data: Jackson, Wee, Hurtado, Kawachi. Drafting of the manuscript: Jackson. Critical revision of the manuscript for important intellectual content: Jackson, Wee, Hurtado, Kawachi. Administrative, technical, and material support: Kawachi. Obtaining funding and study supervision: Jackson, Kawachi. All authors read and approved the final manuscript.

\section{Acknowledgements}

Dr. Jackson was supported by grant 1UL1 TR001102-07, and Dr. Wee by a National Institutes of Health Mid-Career Mentorship Award (K24 DK087932). Funding sources were not involved in the data collection, data analysis, manuscript writing, and publication. The authors have no conflicts of interest to report. The first author, with full access to the data, takes responsibility for data integrity and the data analysis accuracy. This work was presented, in part, at The Obesity Society Conference in Boston, Massachusetts from November 2-7, 2014.

\section{Author details}

${ }^{1}$ Clinical and Translational Science Center, Harvard Catalyst, Harvard Medical School, Boston, MA, USA. ${ }^{2}$ Division of General Medicine and Primary Care, Department of Medicine, Beth Israel Deaconess Medical Center, Harvard Medical School, Boston, MA, USA. ${ }^{3}$ Oregon Institute of Occupational Health Sciences, Oregon Health \& Science University, Portland, OR, USA.

${ }^{4}$ Department of Social and Behavioral Sciences, Harvard T.H. Chan School of Public Health, Boston, MA, USA.

Received: 18 August 2015 Accepted: 18 March 2016

Published online: 02 April 2016

\section{References}

1. Ogden CL, Yanovski SZ, Carroll MD, Flegal KM. The epidemiology of obesity. Gastroenterology. 2007;132(6):2087-102

2. Adami HO, Trichopoulos D. Obesity and mortality from cancer. N Engl J Med. 2003;348(17):1623-4.

3. Adams KF, Schatzkin A, Harris TB, Kipnis V, Mouw T, Ballard-Barbash R, et al. Overweight, obesity, and mortality in a large prospective cohort of persons 50 to 71 years old. N Engl J Med. 2006;355(8):763-78.

4. Visscher TL, Seidell JC. The public health impact of obesity. Annu Rev Public Health. 2001;22:355-75.

5. http://www.bls.gov/news.release/pdf/atus.pdf. American Time Use Survey 2012. Accessed March 2016.

6. French SA, Jeffery RW, Forster JL, McGovern PG, Kelder SH, Baxter JE. Predictors of weight change over two years among a population of working adults: the Healthy Worker Project. Int J Obes Relat Metab Disord. 1994;18(3):145-54.

7. Geliebter A, Gluck ME, Tanowitz M, Aronoff NJ, Zammit GK. Work-shift period and weight change. Nutrition. 2000;16(1):27-9.

8. Steenland K, Burnett C, Lalich N, Ward E, Hurrell J. Dying for work: The magnitude of US mortality from selected causes of death associated with occupation. Am J Ind Med. 2003;43(5):461-82.

9. Schulte PA. Characterizing the burden of occupational injury and disease. J Occup Environ Med. 2005:47(6):607-22.

10. Schulte PA, Wagner GR, Ostry A, Blanciforti LA, Cutlip RG, Krajnak KM, et al. Work, obesity, and occupational safety and health. Am J Public Health. 2007; 97(3):428-36.

11. Perbellini L. Job as a risk factor for obesity... the contrary. Med Lav. 2004;95(3):211-22.

12. Schulte PA, Wagner GR, Downes A, Miller DB. A framework for the concurrent consideration of occupational hazards and obesity. Ann Occup Hyg. 2008;52(7):555-66.

13. Brisson C, Larocque B, Moisan J, Vezina M, Dagenais GR. Psychosocial factors at work, smoking, sedentary behavior, and body mass index: a prevalence study among 6995 white collar workers. J Occup Environ Med. 2000;42(1):40-6.

14. Jonsson D, Rosengren A, Dotevall A, Lappas G, Wilhelmsen L. Job control, job demands and social support at work in relation to cardiovascular risk factors in MONICA 1995, Goteborg. J Cardiovasc Risk. 1999;6(6):379-85.

15. Martikainen PT, Marmot MG. Socioeconomic differences in weight gain and determinants and consequences of coronary risk factors. Am J Clin Nutr. 1999;69(4):719-26.
16. Rosmond R, Bjorntorp P. Psychosocial and socio-economic factors in women and their relationship to obesity and regional body fat distribution. Int J Obes Relat Metab Disord. 1999;23(2):138-45.

17. Aldana SG, Pronk NP. Health promotion programs, modifiable health risks, and employee absenteeism. J Occup Environ Med. 2001;43(1):36-46.

18. Pronk NP, Martinson B, Kessler RC, Beck AL, Simon GE, Wang P. The association between work performance and physical activity, cardiorespiratory fitness, and obesity. J Occup Environ Med. 2004; 46(1):19-25.

19. Geaney F, Kelly C, Greiner BA, Harrington JM, Perry IJ, Beirne P. The effectiveness of workplace dietary modification interventions: a systematic review. Prev Med. 2013;57(5):438-47.

20. van Vegchel N, Bosma $H$, Schaufeli W. Reviewing the effort-reward imbalance model: drawing up the balance of 45 empirical studies. Soc Sci Med. 2005:60(5):1117-31.

21. Yamada Y, Kameda M, Noborisaka Y, Suzuki H, Honda M, Yamada S. Excessive fatigue and weight gain among cleanroom workers after changing from an 8-hour to a 12-hour shift. Scand J Work Environ Health. 2001;27(5):318-26.

22. Niedhammer I, Lert F, Marne MJ. Prevalence of overweight and weight gain in relation to night work in a nurses' cohort. Int J Obes Relat Metab Disord. 1996;20(7):625-33.

23. Di Lorenzo L, De Pergola G, Zocchetti C, L'Abbate N, Basso A, Pannacciulli $N$, et al. Effect of shift work on body mass index: results of a study performed in 319 glucose-tolerant men working in a Southern Italian industry. Int J Obes Relat Metab Disord. 2003;27(11):1353-8.

24. Drewnowski A, Specter SE. Poverty and obesity: the role of energy density and energy costs. Am J Clin Nutr. 2004;79(1):6-16.

25. Drewnowski A. Obesity and the food environment: dietary energy density and diet costs. Am J Prev Med. 2004;27(3 Suppl):154-62.

26. Ogden CL, Carroll MD, Kit BK, Flegal KM. Prevalence of obesity and trends in body mass index among US children and adolescents, 1999-2010. JAMA. 2012;307(5):483-90.

27. Linde JA, Nygaard KE, MacLehose RF, Mitchell NR, Harnack LJ, Cousins JM, et al. HealthWorks: results of a multi-component group-randomized worksite environmental intervention trial for weight gain prevention. Int J Behav Nutr Phys Act. 2012;9:14

28. Salinardi TC, Batra P, Roberts SB, Urban LE, Robinson LM, Pittas AG, et al. Lifestyle intervention reduces body weight and improves cardiometabolic risk factors in worksites. Am J Clin Nutr. 2013;97(4):667-76.

29. Tamers SL, Beresford SA, Cheadle AD, Zheng Y, Bishop SK, Thompson B. The association between worksite social support, diet, physical activity and body mass index. Prev Med. 2011;53(1-2):53-6.

30. Estabrook B, Zapka J, Lemon SC. Evaluating the implementation of a hospital work-site obesity prevention intervention: applying the RE-AIM framework. Health Promot Pract. 2012;13(2):190-7.

31. Kwak L, Kremers SP, Werkman A, Visscher TL, van Baak MA, Brug J. The NHF-NRG In Balance-project: the application of Intervention Mapping in the development, implementation and evaluation of weight gain prevention at the worksite. Obes Rev. 2007:8(4):347-61.

32. Anderson LM, Quinn TA, Glanz K, Ramirez G, Kahwati LC, Johnson DB, et al. The effectiveness of worksite nutrition and physical activity interventions for controlling employee overweight and obesity: a systematic review. Am J Prev Med. 2009:37(4):340-57.

33. Soler RE, Leeks KD, Razi S, Hopkins DP, Griffith M, Aten A, et al. A systematic review of selected interventions for worksite health promotion. The assessment of health risks with feedback. Am J Prev Med. 2010;38(2 Suppl):S237-62.

34. Yancey AK, McCarthy WJ, Taylor WC, Merlo A, Gewa C, Weber MD, et al. The Los Angeles Lift Off: a sociocultural environmental change intervention to integrate physical activity into the workplace. Prev Med. 2004;38(6):848-56.

35. Sorensen G, Barbeau E, Stoddard AM, Hunt MK, Kaphingst K, Wallace L. Promoting behavior change among working-class, multiethnic workers: results of the healthy directions-small business study. Am J Public Health. 2005;95(8):1389-95.

36. DeJoy DM, Southern DJ. An integrative perspective on work-site health promotion. J Occup Med. 1993;35(12):1221-30.

37. National Center for Health Statistics, Centers for Disease Control and Prevention. National Health Interview Survey. Hyattsville, MD. Available at: http://www.cdc.gov/nchs/nhis.htm. Accessed March 2016.

38. Minnesota Population Center and State Health Access Data Assistance Center. Integrated Health Interview Series: Version 3.0. Minneapolis: University of Minnesota; 2010.

39. Wolters KM. Introduction to Variance Estimation. New York: Springer; 1990. 
40. Stata Corp. Stata TX, 2007. 2008. Statistical Software: Released 10. College Station: Stata Corporation; 2010.

41. Rao JN, Scott AJ. A simple method for the analysis of clustered binary data. Biometrics. 1992;48(2):577-85.

42. Barros AJ, Hirakata VN. Alternatives for logistic regression in cross-sectional studies: an empirical comparison of models that directly estimate the prevalence ratio. BMC Med Res Methodol. 2003;3:21.

43. Gu JK, Charles LE, Bang KM, Ma CC, Andrew ME, Violanti JM, et al. Prevalence of obesity by occupation among US workers: the National Health Interview Survey 2004-2011. J Occup Environ Med. 2014;56(5):516-28.

44. Adler NE, Newman K. Socioeconomic disparities in health: pathways and policies. Health Aff (Millwood). 2002;21(2):60-76.

45. Ostry AS, Radi S, Louie AM, LaMontagne AD. Psychosocial and other working conditions in relation to body mass index in a representative sample of Australian workers. BMC Public Health. 2006;6:53.

46. van Amelsvoort LG, Schouten EG, Kok FJ. Duration of shiftwork related to body mass index and waist to hip ratio. Int J Obes Relat Metab Disord. 1999;23(9):973-8.

47. Jackson CL, Redline S, Kawachi I, Williams MA, Hu FB. Racial disparities in short sleep duration by occupation and industry. Am J Epidemiol. 2013; 178(9):1442-51.

48. Jackson CL, Kawachi I, Redline S, Juon HS, Hu FB. Asian-White disparities in short sleep duration by industry of employment and occupation in the US: a cross-sectional study. BMC Public Health. 2014;14:552.

49. Jackson CL, Hu FB, Redline S, Williams DR, Mattei J, Kawachi I. Racial/ethnic disparities in short sleep duration by occupation: the contribution of immigrant status. Soc Sci Med. 2014;118:71-9.

50. Kmec JA, Trimble LB. Does it pay to have a network contact? Social network ties, workplace racial context, and pay outcomes. Soc Sci Res. 2009;38(2):266-78.

51. Hughes D, Dodge MA. African American women in the workplace: relationships between job conditions, racial bias at work, and perceived job quality. Am J Community Psychol. 1997;25(5):581-99.

52. Grandner MA, Hale L, Jackson N, Patel NP, Gooneratne NS, Troxel WM Perceived racial discrimination as an independent predictor of sleep disturbance and daytime fatigue. Behav Sleep Med. 2012;10(4):235-49.

53. Tomfohr L, Pung MA, Edwards KM, Dimsdale JE. Racial differences in sleep architecture: the role of ethnic discrimination. Biol Psychol. 2012;89(1):34-8

54. Thomas KS, Bardwell WA, Ancoli-Israel S, Dimsdale JE. The toll of ethnic discrimination on sleep architecture and fatigue. Health Psychol. 2006; 25(5):635-42.

55. Beihl DA, Liese AD, Haffner SM. Sleep duration as a risk factor for incident type 2 diabetes in a multiethnic cohort. Ann Epidemiol. 2009;19(5):351-7.

56. Karasek RA, T. (1992). Healthy work: stress, productivity, and the reconstruction of working life. New York, New York: Basic books.; 1992.

57. Hall MH, Matthews KA, Kravitz HM, Gold EB, Buysse DJ, Bromberger JT, et al. Race and financial strain are independent correlates of sleep in midlife women: the SWAN sleep study. Sleep. 2009;32(1):73-82.

58. Krieger N, Waterman PD, Hartman C, Bates LM, Stoddard AM, Quinn MM, et al. Social hazards on the job: workplace abuse, sexual harassment, and racial discrimination-a study of Black, Latino, and White low-income women and men workers in the United States. Int J Health Serv. 2006;36(1):51-85.

59. Lieu SJ, Curhan GC, Schernhammer ES, Forman JP. Rotating night shift work and disparate hypertension risk in African-Americans. J Hypertens. 2012;30(1):61-6.

60. Presser H. Race-ethnic and gender differences in nonstandard work shifts. Work Occup. 2003;30:412-39.

61. Braveman PA, Cubbin C, Egerter S, Williams DR, Pamuk E. Socioeconomic disparities in health in the United States: what the patterns tell us. Am J Public Health. 2010;100 Suppl 1:S186-96.

62. Mensah GA, Mokdad AH, Ford ES, Greenlund KJ, Croft JB. State of disparities in cardiovascular health in the United States. Circulation. 2005;111(10):1233-41.

63. Villaneuva AT, Buchanan PR, Yee BJ, Grunstein RR. Ethnicity and obstructive sleep apnoea. Sleep Med Rev. 2005;9(6):419-36.

64. Cawley J. The impact of obesity on wages. J Hum Resour. 2004:39(2):451-74.

65. Lakdawalla D, Philipson T. The growth of obesity and technological change. Econ Hum Biol. 2009:7(3):283-93.

66. Engstrom JL, Paterson SA, Doherty A, Trabulsi M, Speer KL. Accuracy of self-reported height and weight in women: an integrative review of the literature. J Midwifery Womens Health. 2003;48(5):338-45.

67. Gillum RF, Sempos CT. Ethnic variation in validity of classification of overweight and obesity using self-reported weight and height in American women and men: the Third National Health and Nutrition Examination Survey. Nutr J. 2005:4:27.

68. Kuczmarski MF, Kuczmarski RJ, Najjar M. Effects of age on validity of selfreported height, weight, and body mass index: findings from the Third National Health and Nutrition Examination Survey, 1988-1994. J Am Diet Assoc. 2001;101(1):28-34

69. McAdams MA, Van Dam RM, Hu FB. Comparison of self-reported and measured BMI as correlates of disease markers in US adults. Obesity (Silver Spring). 2007;15(1):188-96.

70. Merrill RM, Richardson JS. Validity of self-reported height, weight, and body mass index: findings from the National Health and Nutrition Examination Survey, 2001-2006. Prev Chronic Dis. 2009;6(4):A121.

71. Rowland ML. Self-reported weight and height. Am J Clin Nutr. 1990;52(6):1125-33.

72. Craig BM, Adams AK. Accuracy of body mass index categories based on self-reported height and weight among women in the United States. Matern Child Health J. 2009;13(4):489-96.

73. Villanueva EV. The validity of self-reported weight in US adults: a population based cross-sectional study. BMC Public Health. 2001;1:11.

74. Reis JP, Araneta MR, Wingard DL, Macera CA, Lindsay SP, Marshall SJ. Overall obesity and abdominal adiposity as predictors of mortality in u.s. White and black adults. Ann Epidemiol. 2009;19(2):134-42.

75. Muntaner C, Hadden WC, Kravets N. Social class, race/ethnicity and all-cause mortality in the US: longitudinal results from the 1986-1994 National Health Interview Survey. Eur J Epidemiol. 2004;19(8):777-84.

76. LaVeist TA. Disentangling race and socioeconomic status: a key to understanding health inequalities. J Urban Health. 2005:82(2 Suppl 3):iii26-34.

77. Bleich SN, Thorpe Jr RJ, Sharif-Harris H, Fesahazion R, Laveist TA. Social context explains race disparities in obesity among women. J Epidemiol Community Health. 2010;64(5):465-9.

\section{Submit your next manuscript to BioMed Central and we will help you at every step:}

- We accept pre-submission inquiries

- Our selector tool helps you to find the most relevant journal

- We provide round the clock customer support

- Convenient online submission

- Thorough peer review

- Inclusion in PubMed and all major indexing services

- Maximum visibility for your research

Submit your manuscript at www.biomedcentral.com/submit
BioMed Central 